\title{
Influence of water temperature on the photocatalytic activity of titanium dioxide
}

\author{
Magdalena Janus • Ewelina Kusiak-Nejman • \\ Antoni Waldemar Morawski
}

Received: 16 September 2011/ Accepted: 23 February 2012/Published online: 18 March 2012

(C) The Author(s) 2012. This article is published with open access at Springerlink.com

\begin{abstract}
In this study, it was shown that a possible explanation of increasing photocatalytic activity with temperature may be the fact that with increasing water temperature, the amount of hydroxyl radicals in water also increases, because the ionic product of water increases with an increase in temperature. For measurements of the amount of hydroxyl radicals, the fluorescence technique was used. Terephthalic acid was used as a hydroxyl radical scavenger. After inducing of $\mathrm{TiO}_{2}$, positive holes in the valance band may react with $\mathrm{OH}$ ions and produce ${ }^{\circ} \mathrm{OH}$ radicals, a strong oxidizing agent.
\end{abstract}

Keywords Photocatalysis - Ionic product of water - Hydroxyl radicals · Temperature

\section{Introduction}

The photocatalyst, for example, titanium dioxide $\left(\mathrm{TiO}_{2}\right)$ absorbs light with suitable wavelength in photocatalysis. An electron from the valence band is transferred to the conduction band and creates negative electron $\left(\mathrm{e}^{-}\right)$and positive hole $\left(\mathrm{h}^{+}\right)$. The positively charged hole reacts with chemisorbed $\mathrm{OH}^{-}$groups or water adsorbed on the surface of the photocatalyst to create ${ }^{\bullet} \mathrm{OH}$ radicals and hydrogen cations (Eq. 1) or reacts with hydroxyl groups to create ${ }^{\bullet} \mathrm{OH}$ radical (Eq. 2). Simultaneously, negative electrons react with oxygen to create the anion radical superoxide (Eq. 3).

M. Janus $(\bowtie) \cdot$ E. Kusiak-Nejman · A. W. Morawski

Institute of Chemical and Environment Engineering, West Pomeranian University of Technology, ul. Pułaskiego 10, 70-322 Szczecin, Poland

e-mail: mjanus@zut.edu.pl

M. Janus

Department of Sanitary Engineering, West Pomeranian University of Technology, Al. Piastów 50, 70-310 Szczecin, Poland 
Photocatalysis is very often used for water cleaning, namely to decompose organic contaminants present in water [1].

$$
\begin{gathered}
\mathrm{h}_{\mathrm{VB}}^{+}+\mathrm{H}_{2} \mathrm{O}_{\mathrm{ads}} \rightarrow{ }^{\bullet} \mathrm{OH}+\mathrm{H}^{+} \\
\mathrm{h}_{\mathrm{VB}}^{+}+\mathrm{OH}_{\mathrm{ads}}^{-} \rightarrow{ }^{\bullet} \mathrm{OH} \\
\mathrm{e}_{\mathrm{CB}}^{-}+\mathrm{O}_{2} \rightarrow \mathrm{O}_{2}^{-} \bullet
\end{gathered}
$$

Hoffmann et al. [2] postulated that in the presence of $\mathrm{O}_{2}$, hydroxyl radicals could be also generated by the reduction of dissolved oxygen by photo-electrons.

In this study, commercial $\mathrm{TiO}_{2}$ - anatase form (Police Chemical Company, Poland) was used as photocatalyst. At different temperatures (20, 30, 40, 50, and $60{ }^{\circ} \mathrm{C}$ ), the amount of produced ${ }^{\circ} \mathrm{OH}$ radicals was measured using the fluorescence technique described by Ishibashi et al. [3]. This fluorescence technique is also used by other researchers for detecting $\mathrm{OH}$ radicals, for example by $\mathrm{Yu}$ et al. [4] for the characterization of mesoporous $\mathrm{TiO}_{2}$ powders obtained by hydrothermal surface fluorination treatment or by Tryba et al. [5] to find the relationship between the crystallinity of $\mathrm{TiO}_{2}$ and the photocatalytic activity. Eremia et al. [6] suggested that the fluorescence method using terephthalic acid to observe the generation of hydroxyl radicals is rapid, efficient, and highly sensitive, and the apparatus used in that kind of measurements is quite simple. It is worth mentioning that there are some different other methods for ${ }^{\bullet} \mathrm{OH}$ radicals determination, for example, using of ${ }^{\bullet} \mathrm{OH}$ radicals scavengers such as: salicylic acid [7], diethanolamine [8], $n$-butanol [9] or using electron spin resonance (ESR) spectroscopy [10, 11]. Yang et al. [13] observed the formation of hydroxyl radicals during the reduction of molecular oxygen by $\mathrm{Fe}(\mathrm{II})$-EDTA.

The role of hydroxyl radicals in the organic pollutant decomposition process was studied by Peiró et al. [14], Vione et al. [15] and Palmisano et al. [16]. Peiró et al. [14] concluded that during phenol decomposition, ${ }^{\bullet} \mathrm{OH}$ radicals were the species involved in the oxidation process carried out in the presence of $\mathrm{O}_{2}$. It was also found that the phenol molecules reacted with hydroxyl radicals giving rise to phenoxy radicals. Vione et al. [15] studied the role of ${ }^{\bullet} \mathrm{OH}$ radicals in photodestruction process of phenol and benzoic acid. Both degradation processes depended on the presence of hydroxyl radicals in reactive solution. Nevertheless, phenol oxidation occurred by means of ${ }^{\bullet} \mathrm{OH}$ radicals, while benzoic acid molecules were decomposed on the surface of $\mathrm{TiO}_{2}$ by means of adsorbed hydroxyl radicals. Palmisano et al. [16] investigated the selectivity of hydroxyl radicals in the partial oxidation of aromatic compounds: nitrobenzene, cyanobenzene, benzoic acid, phenol, 4-chlorophenol, $\mathrm{N}$ phenylacetamide, phenylamine and 1-phenylethanone. They concluded that in the case of pollutants containing an electron donor group, it is possible to observe the $\mathrm{OH}$ radicals attack obtaining two kinds of substitution in ortho- and para-positions.

The main aim of described studies was to present one of trapping routes of positively charged holes created during $\mathrm{TiO}_{2}$ excitation. An increase in water temperature cause an increase in the ionic product of water $\left(\mathrm{OH}^{-}, \mathrm{H}_{3} \mathrm{O}^{+}\right.$anions), which is correlated with the increasing amount of ${ }^{\bullet} \mathrm{OH}$ radicals in aqueous solution. 


\section{Experimental}

Commercial $\mathrm{TiO}_{2}$ - anatase form (Police Chemical Company, Poland) with the specific surface area of $222 \mathrm{~m}^{2} / \mathrm{g}$ was used as the tested photocatalyst.

The yield of generated ${ }^{\circ} \mathrm{OH}$ radicals was measured using the fluorescence technique described in detail by Ishibashi et al. [3] using a fluorescence spectrophotometer (F-2500 Hitachi, Japan). The solution containing photocatalyst and terephthalic acid was irradiated at different temperatures $(20,30,40,50$, and $60{ }^{\circ} \mathrm{C}$ ) for $90 \mathrm{~min}$ (samples were taken every $10 \mathrm{~min}$ ). $0.02 \mathrm{~g}$ of the photocatalyst was added to $100 \mathrm{~mL}$ of terephthalic acid solution with a concentration of $830 \mathrm{mg} / \mathrm{L}$ $\left(5 \times 10^{-4} \mathrm{M}\right)$. The ${ }^{\circ} \mathrm{OH}$ radicals are generated by means of UV-Vis light illumination $\left(6 \times 20 \mathrm{~W}\right.$ UV-Vis lamps, Philips, radiation intensity $154 \mathrm{~W} / \mathrm{m}^{2}$ of $\mathrm{UV}$ and $100 \mathrm{~W} / \mathrm{m}^{2}$ of Vis) react with terephthalic acid molecules to produce highly fluorescent 2-hydroxyterephthalic acid which can be easily measured using simple fluorimeters. The use of terephthalic acid was also made due to the formation of only one isomer in the reaction [7, 17]. According to Ishibashi's paper, the intensity of the peak attributed to 2-hydroxyterephthalic acid was known to be proportional to the amount of ${ }^{\bullet} \mathrm{OH}$ radicals. Phenol decomposition with concentration of $10 \mathrm{mg} / \mathrm{L}$ at different temperatures $\left(20,30,40,50\right.$, and $\left.60{ }^{\circ} \mathrm{C}\right)$ was conducted to determine the photocatalytic activity of $\mathrm{TiO}_{2}$ at different range of temperatures. The phenol degradation was carried out for $5 \mathrm{~h}$ under UV-Vis light illumination. The mineralization rate of phenol and its derivatives after $5 \mathrm{~h}$ of $\mathrm{UV}-\mathrm{Vis}$ irradiation was also estimated using TOC (Total Organic Carbon) analyzer (Jena, Germany).

\section{Results and discussion}

Fig. 1 presents the amount of 2-hydroxyterephthalic acid (fluorescence intensity) produced in terephthalic acid solution in the presence of photocatalyst during 90 min of UV-Vis light irradiation at different temperatures. It is possible to observe that with the time of irradiation, the concentration of 2-hydroxyterephthalic acid increases because higher amounts of hydroxyl radicals formed during UV-Vis exposition react with terephthalic acid molecules to create 2-hydroxyterephthalic acid. Fig. 2 presents the amount of 2-hydroxyterephthalic acid produced at different temperatures, for example, after 20,30, and $40 \mathrm{~min}$ of $\mathrm{UV}-\mathrm{V}$ is light illumination in comparison to ionic product of water at different temperatures. The values of ionic product of water at different temperatures are presented in Table 1 [12]. The ionic product of water increases with temperature rise what is correlated with the increase of hydroxyl anions concentration in water. In aqueous solution, the created holes in the $\mathrm{TiO}_{2}$ valence band are trapped by hydroxyl anions present in water, thereupon hydroxyl radicals are formed. The rise of hydroxyl anion concentration with increasing temperature conduces the hole trapping process with higher efficiency. The higher concentration of hydroxyl ions, the higher the amount of the trapped holes, thus the higher the amount of ${ }^{\bullet} \mathrm{OH}$ radicals and 2-hydroxytepephthalic acid. It is possible to conclude that the use of $\mathrm{TiO}_{2}$ under elevated temperature could impact on increase of photocatalytic activity of $\mathrm{TiO}_{2}$. 


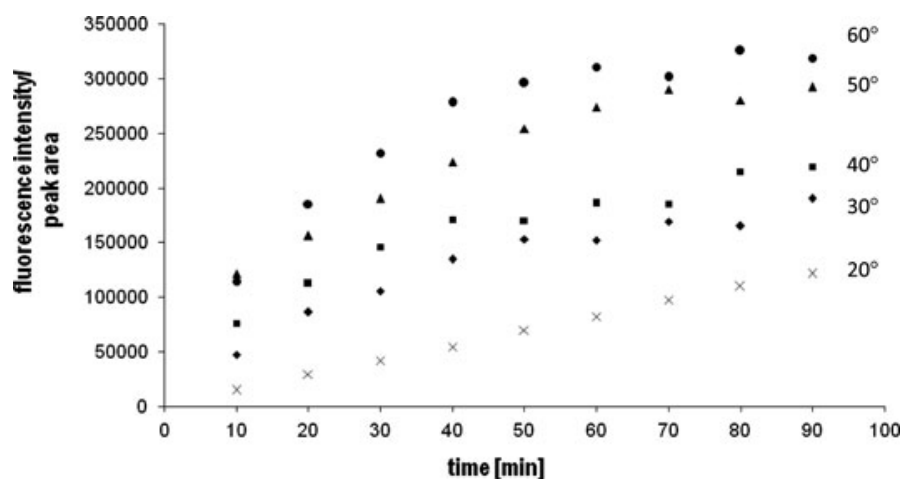

Fig. 1 The amount of 2-hydroxyterephthalic acid (fluorescence intensity) produced during 90 min of UV-Vis light irradiation. $0.02 \mathrm{~g}$ of $\mathrm{TiO}_{2}$ photocatalyst was placed in $100 \mathrm{ml}$ of the water solution of terephthalic acid $\left(5 \times 10^{-4} \mathrm{M}\right)$ at different temperatures: $20,30,40,50$, and $60{ }^{\circ} \mathrm{C}$

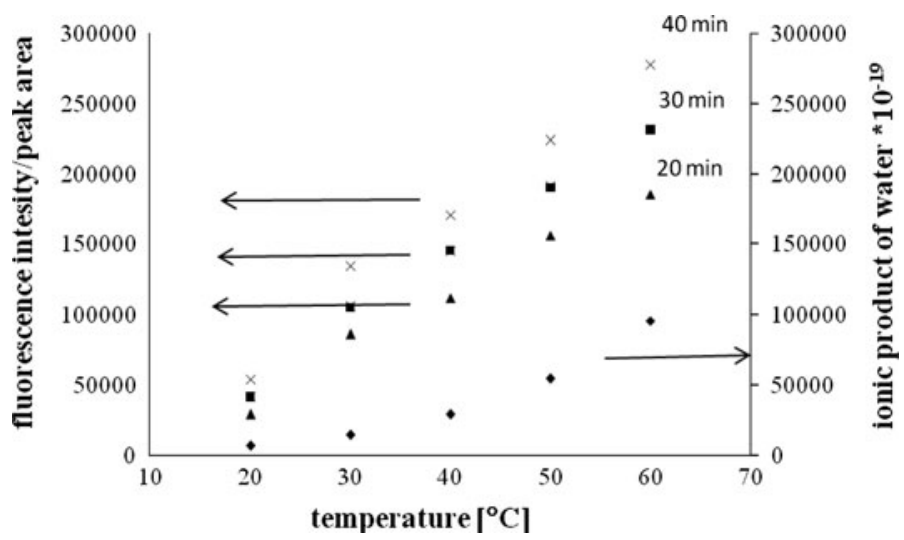

Fig. 2 The amount of 2-hydroxyterephthalic acid at different temperatures after 20, 30, and 40 min of UV-Vis light irradiation in comparison to ionic product of water at different temperatures

Table 1 The ionic product of water at different temperatures

\begin{tabular}{ll}
\hline Temperature $\left[{ }^{\circ} \mathrm{C}\right]$ & $\mathrm{K}_{\mathrm{w}} \cdot 10^{-14}$ \\
\hline 20 & 0.6814 \\
30 & 1.469 \\
40 & 2.918 \\
50 & 5.474 \\
60 & 9.614
\end{tabular}

To prove that elevated temperature affects ${ }^{\bullet} \mathrm{OH}$ radical formation and photocatalytic efficiency, an experiment with phenol decomposition under UV-Vis light irradiation at different temperatures was also conducted. First, the influence of different temperatures onto phenol and terephthalic acid adsorption on the surface of used $\mathrm{TiO}_{2}$ was tested. Each adsorption experiment was repeated twice to check the stability of titanium dioxide surface with regard to adsorption abilities of $\mathrm{TiO}_{2}$. The 
adsorption in the darkness was carried out for $1 \mathrm{~h}$, nevertheless, the concentration of phenol and terephthalic acid was checked after $30 \mathrm{~min}$ and $1 \mathrm{~h}$ of stirring. For terephthalic acid, no changes in concentration after $30 \mathrm{~min}$ and $1 \mathrm{~h}$ were observed whilst for phenol, the concentration decreased insignificantly and after $1 \mathrm{~h}$ of stirring in the darkness (from 1.15 to $0.34 \%$ for $\mathrm{TiO}_{2}$ stirred at 20 and $60{ }^{\circ} \mathrm{C}$, respectively). It was accepted that there is no influence of temperature on the adsorption rate of phenol and terephthalic acid. As can be seen from Fig. 3, the decomposition rate of phenol and derivatives rises with temperature increase. Moreover, the mineralization rate after $5 \mathrm{~h}$ of UV-Vis light irradiation is presented in Fig. 4. At $20{ }^{\circ} \mathrm{C}$, the mineralization amounted to $44.3 \%$ while mineralization at 50 and $60{ }^{\circ} \mathrm{C}$ amounted 90.4 and $91.4 \%$, respectively. As it can be noticed, the efficiency of phenol and by-product decomposition carried out at 50 and $60{ }^{\circ} \mathrm{C}$ is almost the same value. It could be presumed that the temperature of $50{ }^{\circ} \mathrm{C}$ is an optimal temperature for phenol degradation under UV-Vis illumination.

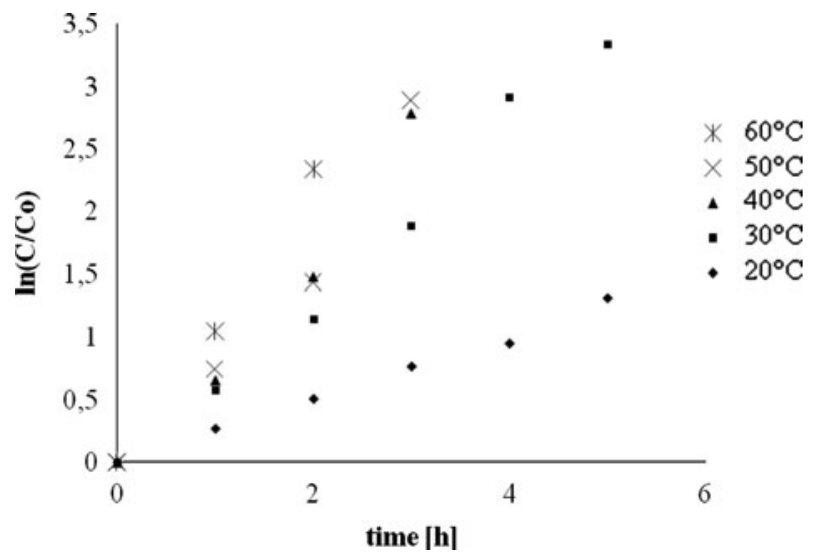

Fig. 3 The rate of phenol decomposition during $5 \mathrm{~h}$ of UV-Vis light irradiation at different temperatures

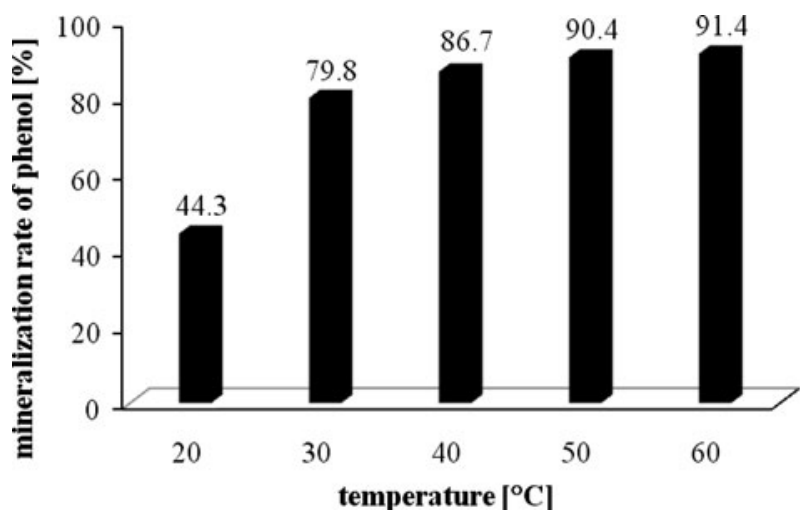

Fig. 4 Mineralization rates of phenol at different temperatures after $5 \mathrm{~h}$ of UV-Vis light exposition 
It should be mentioned that there is no linear dependence between phenol decomposition and hydroxyl radical formation because of the presence of the phenol derivatives in the tested solution. During the UV-Vis exposure, it was possible to detect phenol, benzoquinone and hydroquinone as co-products of phenol decomposition. Part of the $\mathrm{OH}$ radicals was used to oxidize phenolic mentioned coproducts. The reaction between phenol molecules and superoxide radicals could not be eliminate but it is very well known the reaction rate constant of phenol with ${ }^{\bullet} \mathrm{OH}$ radicals highly exceeds the reaction rate constant of phenol with $\mathrm{O}_{2}^{-\bullet}$.

\section{Conclusion}

In this study it was found that an increase of aqueous solution temperature in the presence of excited $\mathrm{TiO}_{2}$ leads to improvement of the efficiency of phenol and byproducts decomposition. It was proved that efficiency improvement is correlated with the increase of the ionic product of water, which rise with temperature, thereby rises the concentration of hydroxyl ions. In that situation, $\mathrm{OH}$ ions could rapidly react with positively charged holes from the surface of excited titania forming higher amount of hydroxyl radicals which can easily oxidize phenol and by-product molecules. The temperature of $50{ }^{\circ} \mathrm{C}$ was found to be the optimal for phenol photodestruction.

Acknowledgments This work was supported by the Polish Ministry of Science and Higher Education as a scientific project N N209 088238 (2010-2012).

Open Access This article is distributed under the terms of the Creative Commons Attribution License which permits any use, distribution, and reproduction in any medium, provided the original author(s) and the source are credited.

\section{References}

1. Herrmann J-M (2010) J Photochem Photobiol A Chem 216:85-93

2. Hoffmann MR, Martin ST, Choi WY, Bahnemann DW (1999) Chem Rev 95:69-96

3. Ishibashi K, Fujishima A, Watanabe T, Hashimoto K (2000) Electrochem Commun 2:207-210

4. Yu J, Wang W, Cheng B, Su B-L (2009) J Phys Chem C 113:6743-6750

5. Tryba B, Toyoda M, Morawski AW, Nonaka R, Inagaki M (2007) Appl Catal B 71:163-168

6. Eremia SAV, Chevalier-Lucia D, Radu G-L, Marty J-L (2008)Talanta 77:858-862

7. Chang Ch-Y, Hsieh Y-H, Hsieh L-L, Yao K-S, Cheng T-Ch (2009) J Hazard Mater 166:897-903

8. Billany MR, Khatib K, Gordon M, Sugden JK (1996) Int J Pharm 137:143-147

9. Marugán J, Hufschmidt D, López-Muñoz M-J, Selzer V, Bahnemann D (2006) Appl Catal B 62:201-207

10. Nakaoka Y, Nosaka Y (1997) J Photochem Photobiol A Chem 110:299-305

11. Shimizu N, Ogino Ch, Dadjour MF, Ninomiya K, Fujihira A, Sakiyama K (2008) Ultrason Sonochem 15:988-994

12. Physicochemical compendium (Poradnik fizykochemiczny) (1974) Wydawnictwo Naukowo-Techniczne, Warszawa

13. Yang X-F, Guo X-Q (2001) Analyst 126:928-932

14. Peiró AM, Ayllón JA, Peral J, Doménech X (2001) Appl Catal B 30:359-373 
15. Vione D, Minero C, Maurino V, Carlotti ME, Picatonatto T, Pelizzetti E (2005) Appl Catal B 58:81-90

16. Palmisano G, Addamo M, Augugliaro V, Caronna T, Di Paola A, García López E, Loddo V, Marcì G, Palmisano L, Schiavello M (2007) Catal Today 122:118-127

17. Saran M, Summer KH (1999) Free Radical Res 31:429-436 